University of Wollongong

Research Online

Australian Institute for Innovative Materials -

Papers

Australian Institute for Innovative Materials

$1-1-2015$

Effective enhancement of the electrochemical performance of layered cathode Li1.5Mn0.75Ni0.2502.5 via a novel facile molten salt method

Zhuo Zheng

Sichuan University

Wei-Bo Hua

Sichuan University

S Liao

Sichuan University

Yan Jun Zhong

Sichuan University

En-Hui Wang

Sichuan University

See next page for additional authors

Follow this and additional works at: https://ro.uow.edu.au/aiimpapers

Part of the Engineering Commons, and the Physical Sciences and Mathematics Commons

Research Online is the open access institutional repository for the University of Wollongong. For further information contact the UOW Library: research-pubs@uow.edu.au 


\title{
Effective enhancement of the electrochemical performance of layered cathode Li1.5Mn0.75Ni0.2502.5 via a novel facile molten salt method
}

\begin{abstract}
A series of nanocrystalline lithium-rich cathode materials $\mathrm{Li}_{1.5} \mathrm{Mn}_{0.75} \mathrm{Ni}_{0.25} \mathrm{O}_{2.5}$ have been prepared by a novel synthetic process, which combines the co-precipitation method and a modified molten salt method. By using a moderate excess of $0.5 \mathrm{LiNO}_{3}-0.5 \mathrm{LiOH}$ eutectic salts as molten media and reactants, the usage of deionized water or alcohol in the subsequent wash process is successfully reduced, compared with the traditional molten salt method. The materials with different excess Li salt content, $\mathrm{Li} / \mathrm{M}(\mathrm{M}=\mathrm{Ni}+\mathrm{Mn})=$ $1.55,1.65,1.75,1.85,1.95,2.05$, molar ratio, show distinct differences in their structure and chargedischarge characteristics. The structural characterization demonstrates that the sample with a ratio of $\mathrm{Li} / \mathrm{M}=1.85$ has a more well-defined alpha- $\mathrm{NaFeO}_{2}$ structure and a more enlarged $\mathrm{Li}$ layer spacing. It also exhibits the best comprehensive electrochemical behavior with the highest coulombic efficiency, the best rate capability and optimal cycling stability. More specifically, it delivers a dramatically improved initial coulombic efficiency of $87.86 \%$, and a discharge capacity of $129 \mathrm{~mA} \mathrm{~h} \mathrm{~g}^{-1}$ even at an ultra-high current density of $2000 \mathrm{~mA} \mathrm{~g}^{-1}$ (10C). Meanwhile a superior cycling stability is also observed with a high discharge capacity of $251 \mathrm{~mA} \mathrm{~h} \mathrm{~g}^{-1}$ and a retention of $98 \%$ at $0.2 \mathrm{C}$ after 50 cycles. Our results reveal that this method is facile and feasible to synthesize a high rate and high capacity lithium-rich material.
\end{abstract}

\section{Keywords}

via, 5, 25o2, 75ni0, 5mn0, li1, cathode, layered, performance, electrochemical, enhancement, effective, salt, method, molten, facile, novel

\section{Disciplines}

Engineering | Physical Sciences and Mathematics

\section{Publication Details}

Zheng, Z., Hua, W., Liao, S., Zhong, Y., Wang, E., Xu, B., Liu, H. \& Zhong, B. (2015). Effective enhancement of the electrochemical performance of layered cathode $\mathrm{Li}_{1} .5 \mathrm{Mn}_{0.75} \mathrm{Ni}_{0.25} \mathrm{O}_{2.5}$ via a novel facile molten salt method. RSC Advances: an international journal to further the chemical sciences, 5 (72), 58528-58535.

\section{Authors}

Zhuo Zheng, Wei-Bo Hua, S Liao, Yan Jun Zhong, En-Hui Wang, Bin-Bin Xu, Hua-Kun Liu, and Ben-He Zhong 


\title{
Journal Name
}

\section{ARTICLE}

\section{Effective Enhancement of Electrochemical Performance for Layered Cathode $\mathrm{Li}_{1.5} \mathbf{M n}_{0.75} \mathrm{Ni}_{0.25} \mathrm{O}_{2.5}$ via A Novel Facile Molten Salt Method}

\author{
Zhuo Zheng, ${ }^{a}$ Wei-Bo Hua, ${ }^{a}$ Shi-Xuan Liao, ${ }^{a}$ Yan-Jun Zhong, ${ }^{a}$ En-Hui Wang, ${ }^{a}$ \\ Bin-Bin Xu, ${ }^{b}$ Hua-Kun Liu ${ }^{c}$ and Ben-He Zhong* ${ }^{a}$
}

\begin{abstract}
A series of nanocrystalline lithium-rich cathode materials $\mathrm{Li}_{1.5} \mathrm{Mn}_{0.75} \mathrm{Ni}_{0.25} \mathrm{O}_{2.5}$ have been prepared by a novel synthetic process, which is combined with the co-precipitation method and the modified molten salt method. By using the moderate excessive $0.5 \mathrm{LiNO}_{3}-0.5 \mathrm{LiOH}$ eutectic as molten media and reactants, the usage of the deionized water or alcohol in the subsequent wash process is successfully reduced, compared with the traditional molten salt method. The materials with different excessive $\mathrm{Li}$ salts content, $\mathrm{Li} / \mathrm{M}(\mathrm{M}=\mathrm{Ni}+\mathrm{Mn})=1.55,1.65,1.75$, $1.85,1.95,2.05$, molar ratio, show distinct differences in structure and charge/discharge characteristics. The structural characterization demonstrates that the sample with the ratio of $\mathrm{Li} / \mathrm{M}=1.85$ has more well-defined $\alpha-\mathrm{NaFeO}_{2}$ structure and more enlarged $\mathrm{Li}$ layer spacing. And it exhibits the best comprehensive electrochemical behaviors with the highest coulombic efficiency, best rate capability and optimal cycling stability. More specifically, it delivers a dramatically improved initial coulombic efficiency of $87.86 \%$, and a discharge capacity of 129 $\mathrm{mAh} \mathrm{g}^{-1}$ even at an ultra-high current density of $2000 \mathrm{~mA} \mathrm{~g}^{-1}(10 \mathrm{C})$, meanwhile the superior cycling stability is also observed with a high discharge capacity of $251 \mathrm{mAh} \mathrm{g}^{-1}$ and retention of $98 \%$ at $0.2 \mathrm{C}$ after 50 cycles. Our results reveal that this method is facile and feasible to synthesize a high rate and high capacity lithium-rich material.
\end{abstract}

\section{Introduction}

Rechargeable lithium ion batteries (LIBs) with high energy and high power densities are essential for the fast development of portable electronics, electric vehicles (EVs) and hybrid electric vehicles (HEVs). ${ }^{1-7}$ To meet the demand, a new cathode with high energy density is desiderated to be developed. Currently, the family of lithium-rich layered oxides $\mathrm{Li}_{1+y} \mathrm{M}_{1-y} \mathrm{O}_{2}$ (also write as $x \mathrm{Li}_{2} \mathrm{MnO}_{3} \cdot(1-$ $x) \mathrm{LiMO}_{2}, \mathrm{M}=\mathrm{Ni}, \mathrm{Co}, \mathrm{Mn}$ ) have attracted much attention, due to their encouraging high reversible capacity over $250 \mathrm{mAh} \mathrm{g}^{-1}$ when initially charged above $4.5 \mathrm{~V} \cdot{ }^{8-10}$ Among these lithium-rich oxides, the Li-rich Mn-based nickel oxide $\mathrm{Li}_{1.5} \mathrm{Mn}_{0.75} \mathrm{Ni}_{0.25} \mathrm{O}_{2.5}$ is the most appealing one due to its high discharge capacity, low cost, good safety and less toxicity. ${ }^{11-13}$ However, it suffers several serious drawbacks needed to be resolved, such as its intrinsically inferior rate capability, poor cycle performance, a large irreversible capacity loss (ICL) in the initial cycle, and voltage decay during long-term cycling resulting from phase transformation from layered to spinel/layered intergrowth structure. ${ }^{14-16}$

To address these obstacles, many strategies have been developed, especially regarding the synthesis methods. At present, many synthetic routes have been reported, ${ }^{17-20}$ including solid state reaction, co-precipitation method, sol-gel method, molten salt synthetic method and others. Among these methods, the molten salt method is a simple and versatile way to prepare highly crystalline cathode materials by using molten salt as the solvent and/or reactants. $^{21-25}$ Additionally, in the molten liquid environment, reactions are primarily decided by chemical equilibria and proceed much faster than the diffusion controlled by solid-state reactions. ${ }^{20,25}$ Despite of these advantages, some inherent shortcomings are also existed, such as the molten salts of $\mathrm{KCl}, \mathrm{NaCl}, \mathrm{KNO}_{3}$ or $\mathrm{LiNO}_{3}-\mathrm{LiCl}$ eutectic are much excessive than the starting transition metal salts for the sake of providing sufficient liquid condition to promote the transition metal atoms diffusion, usually, the molar ratio of the $n_{\text {(starting materials) }}: n_{\text {(molten salt) }}$ is $1: 3$ or $1: 4$ or more higher. ${ }^{20-23}$ Hence, it would not only cause the unnecessary water waste and increase environmental pressure because it needs much deionized water or alcohol to wash the product to remove the excess Li-salts or $\mathrm{KCl}$, $\mathrm{NaCl}$ salts, but also increase the cost from an economic perspective for much excessive molten salts are consumed. Furthermore, although the reactions in the molten media are decided by chemical equilibria, if the starting materials cannot be mixed thoroughly, it would also cause the inhomogeneity phases to appear in the product and deteriorate the electrochemical performance. Generally, stoichiometric ratio of $\mathrm{Li}$ salt and transition metal (Mn, Ni, Co) salts and large excess molten salts are mixed through simple mechanical 
grinding in the traditional molten salt method, ${ }^{22,24,25}$ therefore, it is very difficult to achieve molecule-level mixing of these starting materials. Fortunately, the co-precipitation method can compensate this defect and easily realize the molecule-level mixing, and it is considered as the optimum way to get homogeneous and integrated structure, which is the most crucial factor to achieve better electrochemical properties. ${ }^{26}$

In this paper we firstly propose a novel process that combines the hydroxide co-precipitation method and molten salt method to prepare $\mathrm{Li}_{1.5} \mathrm{Mn}_{0.75} \mathrm{Ni}_{0.25} \mathrm{O}_{2.5}$ electrode. It is worth emphasising that the herein molten salt method differs from tradition one, mainly due to we do not need large excessive molten salt in the synthetic route so that the water consumption in the aforementioned process of washing can be drastically reduced. That's because the transition metals are already achieved the molecule-level mixing as $\mathrm{Mn}_{0.75} \mathrm{Ni}_{0.25}(\mathrm{OH})_{2}$ precursor by co-precipitation method. As far as we know, there have been few reports on investigating the effect of the amount of salt flux on the final materials. Hence, we employ a series of moderate excessive $0.5 \mathrm{LiNO}_{3}-0.5 \mathrm{LiOH}$ eutectic as molten media and reactants to synthesize the $\mathrm{Li}_{1.5} \mathrm{Mn}_{0.75} \mathrm{Ni}_{0.25} \mathrm{O}_{2.5}$ material. The structure, morphology and electrochemical performance of these materials are extensively investigated with the gradually incremental $\mathrm{Li}$ salts. Furthermore, we find that when the molar ratio of $\mathrm{Li} / \mathrm{M}(\mathrm{M}=$ $\mathrm{Ni}+\mathrm{Mn}$ ) is 1.85 , the sample exhibits the best rate capability and optimal cyclic stability with the lowest irreversible capacity loss (ICL) in the initial cycle.

\section{Experimental section}

\subsection{Sample preparation}

Layered $\mathrm{Li}_{1.5} \mathrm{Mn}_{0.75} \mathrm{Ni}_{0.25} \mathrm{O}_{2.5}$ material was prepared by a novel method that combined the hydroxide co-precipitation method and molten salt method. Firstly, the $\mathrm{Mn}_{0.75} \mathrm{Ni}_{0.25}(\mathrm{OH})_{2}$ precursor was prepared by co-precipitation method. $\mathrm{NiSO}_{4} \cdot 6 \mathrm{H}_{2} \mathrm{O}$, $\mathrm{MnSO}_{4} \cdot \mathrm{H}_{2} \mathrm{O}(\mathrm{Ni}: \mathrm{Mn}=1: 3$, molar ratio) were dissolved in distilled water, and then pumped into continuous stirred tank reactors (CSTR) under nitrogen atmosphere. Meanwhile, the $\mathrm{NaOH}$ solution $(8 \mathrm{M})$ and the $\mathrm{NH}_{3} \cdot \mathrm{H}_{2} \mathrm{O}$ solution $(2 \mathrm{M})$ were separately fed into the CSTR at $50{ }^{\circ} \mathrm{C}$. The $\mathrm{pH}$ value was carefully controlled at $11.0 \pm 0.2$ and the stirring speed was monitored at around $800 \mathrm{rpm}$. Afterwards, the co-precipitated particles were washed with hot distilled water several times to remove the residual $\mathrm{Na}^{+}$and $\mathrm{SO}_{4}{ }^{2-}$. The powders were dried in a vacuum oven at $90{ }^{\circ} \mathrm{C}$ for $12 \mathrm{~h}$. Then, the $0.5 \mathrm{LiNO}_{3}-0.5 \mathrm{LiOH}$ eutectic mixture was used as molten media and lithium source to mix with the $\mathrm{Mn}_{0.75} \mathrm{Ni}_{0.25}(\mathrm{OH})_{2}$ precursor. The molar ratios of eutectic salts to starting material $\left(n_{(\mathrm{Li})}: n_{(\mathrm{M})}\right)$ were set as 1.55 , $1.65,1.75,1.85,1.95,2.05$, respectively. All samples have $5 \%$ excess $\mathrm{Li}$ salts to compensate for possible Li loss during the calcinations. Correspondingly, the obtained materials were designed as L0, L1, L2, L3, L4 and L5, respectively. The mixture was first heated at $500^{\circ} \mathrm{C}$ for $6 \mathrm{~h}$, and then calcined at $850^{\circ} \mathrm{C}$ for $12 \mathrm{~h}$ in air. Afterwards, these materials were washed with a small amount of hot distilled water, and finally, dried in a vacuum oven at $90{ }^{\circ} \mathrm{C}$ for $10 \mathrm{~h}$ to obtain the final lithiated compounds.

\subsection{Sample characterization}

Lithium content of these compounds was characterized by inductive coupled plasma-atomic emission spectrometer (ICPAES, SPECTRO ARCOS FHS12). Powder X-ray diffraction
(XRD, PW1730, $\mathrm{Cu} \mathrm{K} \alpha$ radiation, $\lambda=1.5418 \AA$ ) was employed to identify the crystalline structures for the as-prepared compounds. The XRD data were collected in the range of $10^{\circ}$ $70^{\circ} 2 \theta$. The particle size and the morphological features were observed by scanning electron microscopy (SEM, S4800). The chemical valence state of $\mathrm{Ni}$ and $\mathrm{Mn}$ were determined by X-ray photoelectron spectroscopy (XPS, PHI QUANTUM2000) with monochromatic Al-K $\alpha$ anode source, and the binding energy (BE) of XPS calibrated with reference to C 1s spectrum of carbon $(284.60 \mathrm{eV})$. The microstructures of these composites were observed by transmission electron micrograph (TEM, JEM-2100).

\subsection{Electrochemical measurement}

Electrochemical properties of these cathode materials were measured with CR2032-type coin cells, which consist of oxide cathode, Li metal anode and a porous polypropylene separator (Celgard 2400) with $1 \mathrm{M} \mathrm{LiPF}_{6}$ solution in EC-DMC (1 : 1 in volume rate) as the electrolyte. The cathodes were prepared by mixing oxide powder, carbon black and polyvinylidene difluoride (PVDF) binder (80:13:7, weight ration) in $\mathrm{N}$ methy pyrrolidone (NMP). The obtained slurry was casted on aluminum foil and dried in a vacuum oven at $100{ }^{\circ} \mathrm{C}$ for $10 \mathrm{~h}$. The foil was cut into discs with diameter of $14 \mathrm{~mm}$, and then pressed prior to use. The loading of the active material in the electrode was $3-4 \mathrm{mg} \mathrm{cm}^{-2}$. All coin cells were assembled and sealed in an argon-filled glove box. The cells were charged and discharged galvanostatically between 2.0 to $4.8 \mathrm{~V}\left(v s . \mathrm{Li} / \mathrm{Li}^{+}\right)$at room temperature with current densities of $0.1 \mathrm{C}, 0.2 \mathrm{C}, 0.5 \mathrm{C}$, $1 \mathrm{C}$, respectively. Above $1 \mathrm{C}$ discharge rates, the cells were charged at $1 \mathrm{C}$ and discharged at the corresponding rates from 3 $\mathrm{C}$ to $10 \mathrm{C}\left(1 \mathrm{C}=200 \mathrm{~mA} \mathrm{~g}^{-1}\right)$. Electrochemical impedance spectroscopy (EIS) measurements were tested on an electrochemical workstation (Zennium, IM6) in the frequency range of $100 \mathrm{kHz}-10 \mathrm{mHz}$ with an alternating-current amplitude of $5 \mathrm{mV}$.

\section{Results and discussion}

ICP-AES analysis data for the atomic compositions of the assynthesized materials are listed in Table 1 . It is illustrated that the ratios of $\mathrm{Ni}: \mathrm{Mn}$ and $\mathrm{Li} /[\mathrm{Ni}+\mathrm{Mn}]$ in all the samples are approximately consistent with the expected $\mathrm{Li}_{1.5} \mathrm{Mn}_{0.75} \mathrm{Ni}_{0.25} \mathrm{O}_{2.5}$ stoichiometry within experimental errors.

Table 1 ICP-AES analysis results of $\mathrm{Ni}: \mathrm{Mn}$ and $\mathrm{Li} /[\mathrm{Mn}+\mathrm{Ni}]$ molar ratios in these samples

\begin{tabular}{ccc}
\hline Sample & $\mathrm{Ni}: \mathrm{Mn}$ & $\mathrm{Li} /[\mathrm{Ni}+\mathrm{Mn}]$ \\
\hline L0 & $0.248: 0.750$ & 1.498 \\
L1 & $0.250: 0.751$ & 1.499 \\
L2 & $0.249: 0.751$ & 1.501 \\
L3 & $0.251: 0.750$ & 1.502 \\
L4 & $0.252: 0.752$ & 1.502 \\
L5 & $0.252: 0.753$ & 1.504 \\
\hline
\end{tabular}

Fig. 1 shows the XRD patterns for these samples. As shown in Fig. 1a, all the samples exhibit the similar XRD patterns. The majority of the diffraction peaks are relatively 
strong and can be well indexed as a rhombohedral layered phase $(\mathrm{R} \overline{3} \mathrm{~m})$ which is normally taken as the layered characteristic of $\mathrm{LiMO}_{2}(\mathrm{M}=\mathrm{Ni}, \mathrm{Mn})$ structure, ${ }^{27,}{ }^{28}$ while a series of weak reflections at $20^{\circ}-23^{\circ}(2 \theta$ value) are consistent with the hexagonal $\mathrm{LiMn}_{6}$ super-ordering in $\mathrm{Li}_{2} \mathrm{MnO}_{3}$ monoclinic phase with $\mathrm{C} 2 / \mathrm{m}$ symmetry. ${ }^{27,28}$ Combined with the ICP analysis above (Table 1), it can be concluded that the $\mathrm{Li}_{1.5} \mathrm{Mn}_{0.75} \mathrm{Ni}_{0.25} \mathrm{O}_{2.5}$ lithium-rich material is successfully synthesized via this novel molten salt method. Compared with the traditional molten salt method, fewer molten salts are used in our synthetic route, but interestingly, the highly crystalline materials still can be prepared at the similar calcination temperature with the traditional molten salt method. This reason can be ascribed to the molecule-level mixing of transition metal salts which is derived from the co-precipitation process. The diffraction peaks of $\mathrm{Li}_{2} \mathrm{MnO}_{3}$ phase are changed significantly (marked by yellow dotted line in Fig. 1a), so the detailed comparison of peaks change are depicted in the selective patterns in $2 \theta$ range of $20.0-22.0^{\circ}$, as shown in Fig. $1 \mathrm{~b}$. As can be seen, the peaks of $\mathrm{Li}_{2} \mathrm{MnO}_{3}$ phase become clearer with the increased Li content, indicating the higher crystallinity.
This reason can be legitimately attributed to the $0.5 \mathrm{LiNO}_{3}$ $0.5 \mathrm{LiOH}$ eutectic mixture with a lower melting point that can introduce some liquid to the system, and thus promoting the reaction activation and lowering the reaction temperature. ${ }^{21,23 \text {, }}$ 25 Therefore, at the same calcination temperature, the more $0.5 \mathrm{LiNO}_{3}-0.5 \mathrm{LiOH}$ eutectic mixture added, the higher crystallization degree achieved. Rietveld refinements within layered $\mathrm{LiMO}_{2}(\mathrm{R} \overline{\mathrm{3}} \mathrm{m})$ phase are conducted using TOPAS software to illustrate the variations from the view of lattice parameters. The refinement results are listed in Table 2. The lattice constant $a$ shows little change, however, the $c$-lattice parameter is changed obviously. The $c$-lattice parameter is perpendicular to the Li layer in the layered structure, therefore, its increase signifies an enlargement of Li layer spacing. ${ }^{29}$ The L3 sample exhibits the largest $c$-lattice parameter, which may cause a substantially higher Li diffusivity. ${ }^{29}$ Generally, the $c / a$ value is associated with the degree of trigonal distortion: a high $c / a$ value is preferred for well-defined hexagonal $\alpha-\mathrm{NaFeO}_{2}$ structure. $^{30-32}$ Therefore, it can be inferred that the L3 sample has a better layered structure than others.
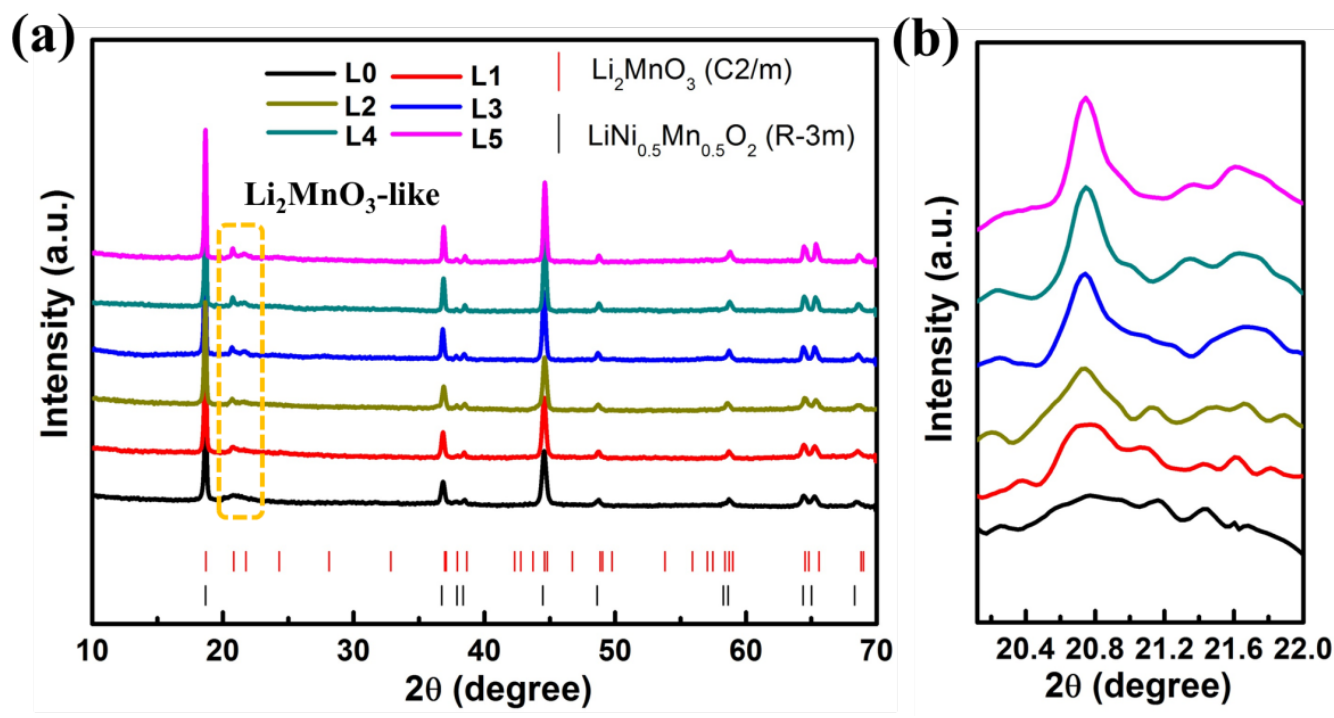

Fig. 1 (a) XRD patterns of these compounds; (b) magnified area in the $20.0-22.0^{\circ} 2 \theta$ region

Table 2 Lattice parameters of these samples

\begin{tabular}{cccccc}
\hline Sample & $a(\AA)$ & $c(\AA)$ & $c / a$ & $\operatorname{Vol}\left(\AA^{3}\right)$ & $R_{\mathrm{wp}}(\%)$ \\
\hline L0 & 2.8550 & 14.2405 & 4.9879 & 100.52 & 4.10 \\
L1 & 2.8571 & 14.2580 & 4.9904 & 100.80 & 3.97 \\
L2 & 2.8555 & 14.2567 & 4.9927 & 100.65 & 3.85 \\
L3 & 2.8547 & 14.2609 & 4.9956 & 100.46 & 4.17 \\
L4 & 2.8580 & 14.2444 & 4.9840 & 100.76 & 4.28 \\
L5 & 2.8584 & 14.2377 & 4.9810 & 100.68 & 4.46 \\
\hline
\end{tabular}

X-ray photoelectron spectroscopy (XPS) measurements are carried out to gain more insight into the oxidation states of transition metals in the as-prepared samples. Fig. 2 shows the typical XPS spectra of Ni 2p and Mn 2p for these samples. All XPS spectra are corrected using $\mathrm{C} 1 \mathrm{~s}$ at $284.60 \mathrm{eV}$. For L0 sample, the $\mathrm{Ni} 2 \mathrm{p}_{3 / 2}$ and $\mathrm{Mn} 2 \mathrm{p}_{3 / 2}$ peaks are observed at $854.5 \mathrm{eV}$ and $642.2 \mathrm{eV}$, respectively, which are consistent with the previous reports for $\mathrm{Ni}^{2+}$ and $\mathrm{Mn}^{4+}$ in the similar oxide cathode materials. ${ }^{33-35}$ However, these peaks in other samples are shifted with the increased $\mathrm{Li}$ content. The $\mathrm{Mn}_{2} \mathrm{p}_{3 / 2}$ peaks are slightly shifted toward lower binding energies, indicating some lower oxidation state than $\mathrm{Mn}^{4+}$ ions appear. Correspondingly, a similar peak shift of $\mathrm{Ni} 2 \mathrm{p}_{3 / 2}$ spectra toward higher binding energies are also observed with $\mathrm{Li}$ content increasing. The increasingly significant characteristics of $\mathrm{Ni}^{3+}$ and $\mathrm{Mn}^{3+}$ may be ascribed to the increase of $0.5 \mathrm{LiNO}_{3}-0.5 \mathrm{LiOH}$ salts which would be decomposed to $\mathrm{Li}_{2} \mathrm{O}$ at the process of high temperature calcination, and the excessive $\mathrm{Li}_{2} \mathrm{O}$ are attached on the surface of the reactant particles, preventing the contact with oxygen, and thus resulting the incomplete oxidation of manganese. It is likely that the increase in oxidation state of $\mathrm{Ni}$ is a compensation of deduction in oxidation state of $\mathrm{Mn}$ ions.

Fig. 3a shows the SEM images of the $\mathrm{Ni}_{0.25} \mathrm{Mn}_{0.75}(\mathrm{OH})_{2}$ precursor. The photographs show that the precursor are agglomerates in micron level, which consists of hexagonal 
nanoplates with a thickness of about $40 \mathrm{~nm}$, and the lateral dimensions range from 200 to $500 \mathrm{~nm}$. Fig. 3b shows the SEM images of as-prepared samples. With the Li content increasing, the particle size in terms of the thickness and the lateral dimensions are gradually increased. Take the thickness of nanoplates for example, the thickness distribution and the average thickness of these samples are shown in Figure S1 in the Supporting Information. As can be seen, the average thickness of L0, L1 and L2 samples are similar, in contrast, it shows dramatic expansion in the thickness of L3, L4 and L5 samples, especially the 55 sample, with an average thickness as high as $244 \mathrm{~nm}$. The significant change of particle size can be ascribed to the excessive $\mathrm{Li}$ salts that can lower the reaction temperature and promote the reaction activation, as mentioned in XRD analysis. In general, the smaller particle size could bespeak the better electrochemical performance. ${ }^{36}$ Nevertheless, the particle crystallinity also affects the stability of parent structure during the repeated $\mathrm{Li}^{+}$ion insertion/extraction
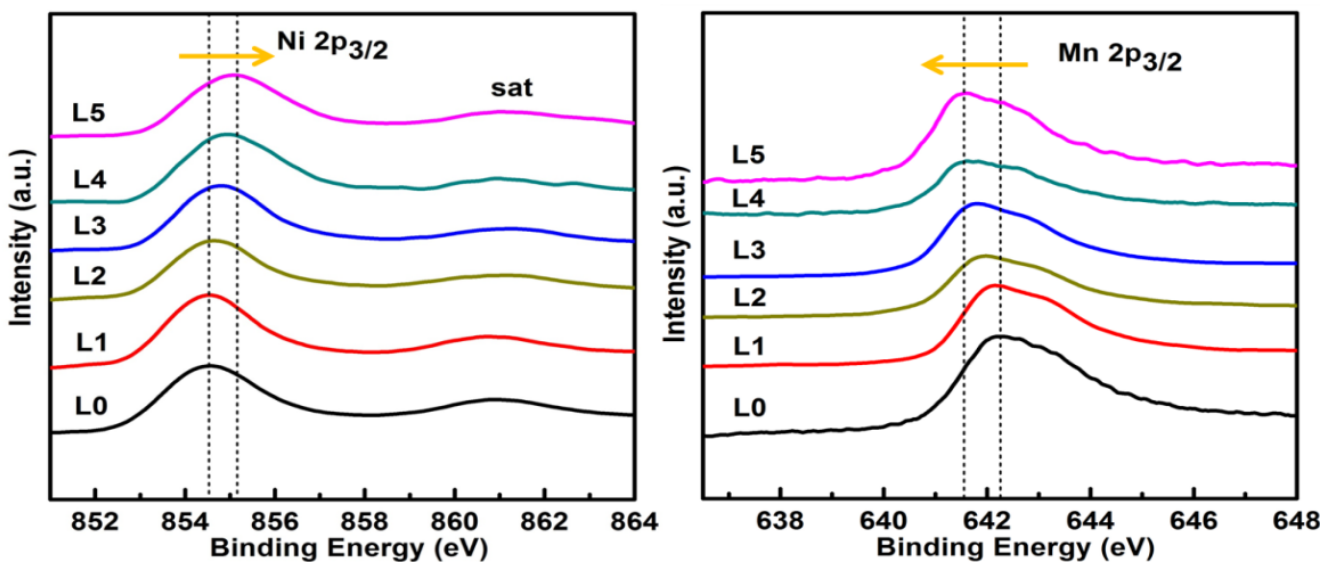

Fig. 2 XPS of Ni 2p and Mn 2p spectra for these samples

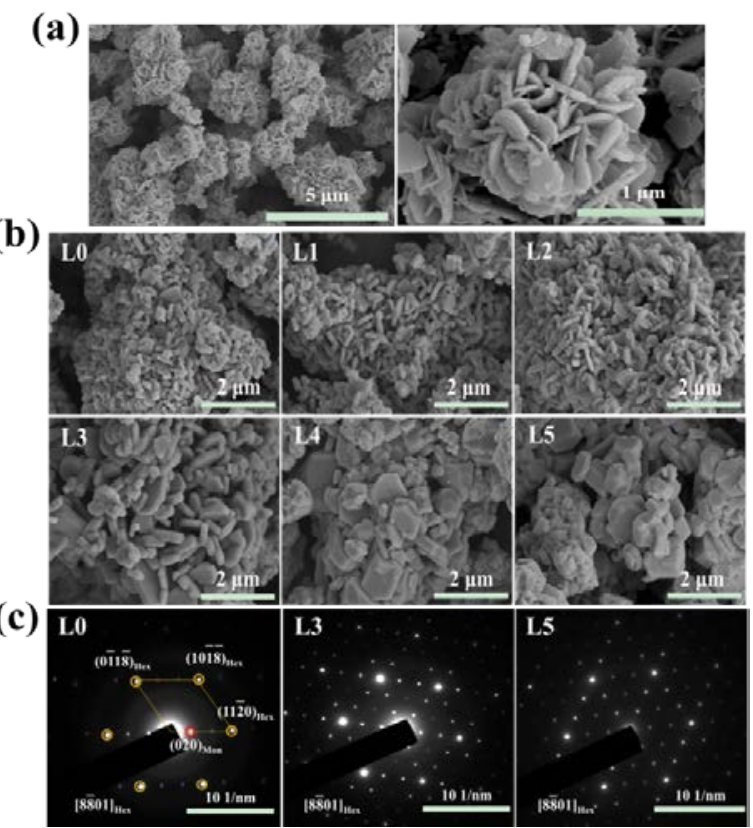

Fig. 3 SEM images of the (a) $\mathrm{Ni}_{0.25} \mathrm{Mn}_{0.75}(\mathrm{OH})_{2}$ precursor, (b) L0 - L5 samples; (c) SAED images of L0, L3 and L5 samples processes, thus affecting the electrochemical properties of material. Although L0, L1 and L2 samples have the smaller primary particle size than L3 sample, their relative lower crystallinity as shown in Fig. 1, may restrict the electrochemical behaviour to a certain degree. Moreover, the average thickness of L4 and L5 samples are increased to $200-300 \mathrm{~nm}$, which is much bigger than L3 sample (157 nm), and the larger thickness indicates much longer $\mathrm{Li}^{+}$diffusion path which is related to a worse rate capability. Fig. 3c shows the SAED images of L0, L3 and L5 samples. It is clear that all the SAED patterns consist of two sets of reflections. The strong hexagonal reflections can be indexed in six-index notation (marked by yellow circle), indicating a $\alpha-\mathrm{NaFeO}_{2}$ layered structure $(\mathrm{R} \overline{3} \mathrm{~m}){ }^{37}$ The weak reflections (marked by red circle), which are associated with $\mathrm{Li}$ ordering in $\mathrm{Li}_{2} \mathrm{MnO}_{3}$-like domains, ${ }^{37}$ are clearly identified between the two bright spots of the layered trigonal symmetry. The SAED patterns also reveal these samples prepared by this novel method are single crystalline.

Fig. 4 shows the first charge-discharge curves during electrochemical cycling of the as-prepared cathode materials at

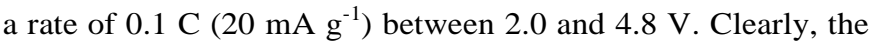
initial charge profiles of these samples show a smooth sloping region below $4.5 \mathrm{~V}$ and a high voltage plateau at around $4.5 \mathrm{~V}$. The sloping region below $4.5 \mathrm{~V}$ can be ascribed to the $\mathrm{Li}^{+}$ deintercalation from layered structure by oxidation of $\mathrm{Ni}^{2+}$ to $\mathrm{Ni}^{4+}{ }^{38,39}$ The plateau at around $4.5 \mathrm{~V}$ can be attributed to the $\mathrm{Li}_{2} \mathrm{MnO}_{3}$ activation which leads to a large initial irreversible capacity loss (ICL). ${ }^{38,}{ }^{39}$ The first coulombic efficiency increases from $77.13 \%$ in L0 to $87.86 \%$ in L3. However, for L4 and L5 samples, the ICL become larger, with lower coulombic efficiencies of $76.85 \%$ and $75.52 \%$, respectively. The enhanced coulombic efficiency for L3 sample can be reasonably attributed to the more well-defined $\alpha-\mathrm{NaFeO}_{2}$ structure which can improve the lattice stability and alleviate the irreversible loss of $\mathrm{Li}_{2} \mathrm{O}$ during the $\mathrm{Li}_{2} \mathrm{MnO}_{3}$ activation. 

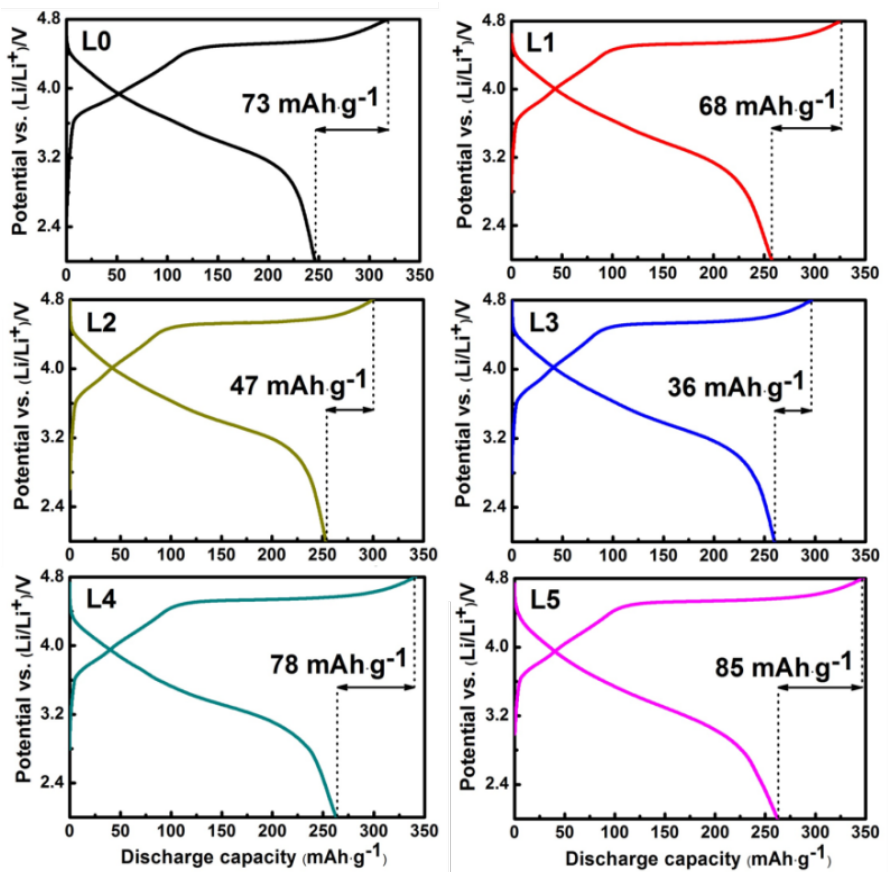

Fig. 4 Initial charge-discharge curves of these cathodes when cycled between 2.0 and $4.8 \mathrm{~V}$ at $0.1 \mathrm{C}\left(20 \mathrm{~mA} \mathrm{~g}^{-1}\right)$

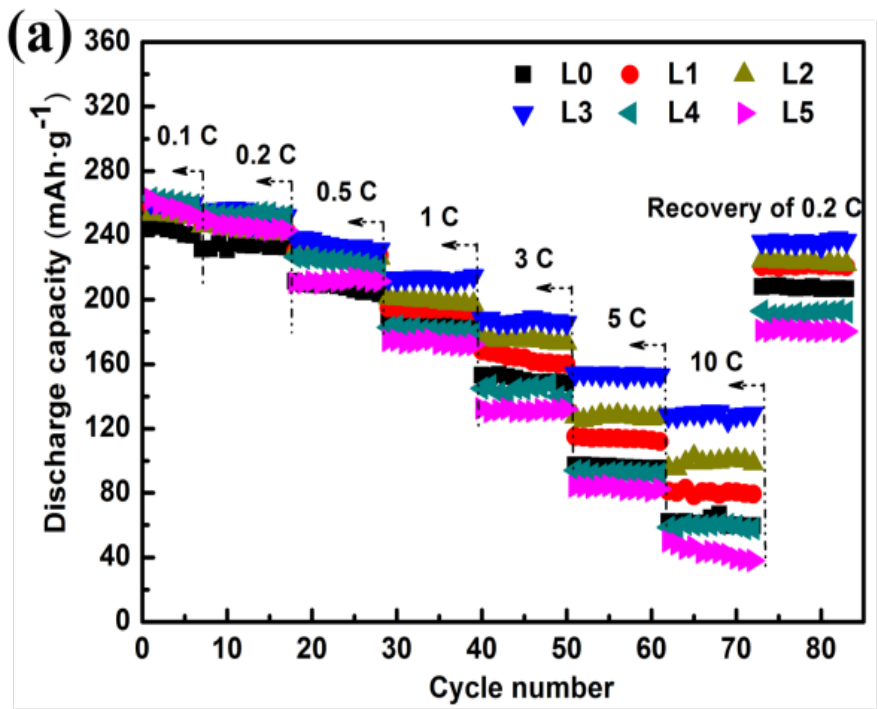

(b)

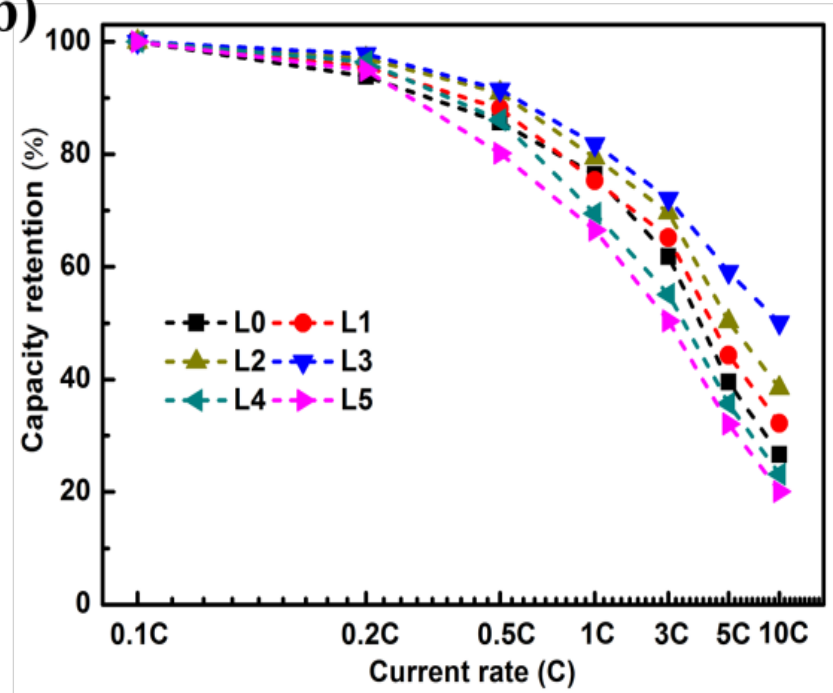

Fig. 5a shows a continuous cycling result at incremental rates from $0.1 \mathrm{C}$ to $10 \mathrm{C}$ then recovering back to $0.2 \mathrm{C}$. As can be seen, the L3 sample exhibits the best rate capability. It yields maximal discharge capacities of 261, 256, 238, 214, 187 and $154 \mathrm{mAh} \mathrm{g}^{-1}$ at $0.1 \mathrm{C}, 0.2 \mathrm{C}, 0.5 \mathrm{C}, 1 \mathrm{C}, 3 \mathrm{C}$ and $5 \mathrm{C}$, respectively. More surprisingly, a maximal capacity of 129 $\mathrm{mAh} \mathrm{g}^{-1}$ is still achieved at $10 \mathrm{C}\left(2000 \mathrm{~mA} \mathrm{~g}^{-1}\right)$. This outstanding rate capability is also observed in the previously excellent reports, ${ }^{10}, 40,41$ which have similar nano-plates morphology with our research. However, the L4 and L5 electrodes show poorer rate capability than other samples. This result is consistent with the above XRD and SEM analysis (Fig. 1 and Fig. 3), which manifest these two samples have inferior layered structure and large nano-plates size. In order to compare the rate capabilities more intuitively, the capacity retention of these samples at $0.2 \mathrm{C}, 0.5 \mathrm{C}, 1 \mathrm{C}, 3 \mathrm{C}, 5 \mathrm{C}$ and 10 $\mathrm{C}$ rates relative to $0.1 \mathrm{C}$ rate are shown in Fig. $5 \mathrm{~b}$ (Note: the capacity retention at $0.1 \mathrm{C}$ is defined to $100 \%$, and the calculation equation can be written as $Q_{(\square \quad \mathrm{C})} / Q_{(0.1}$ C), $Q$ represents the discharge capacity). It is also notable that the L3 sample delivers the highest capacity retention, with capacity retention of $98 \%, 91 \%, 82 \%, 72 \%, 59 \%$ and $50 \%$ at $0.2 \mathrm{C}, 0.5$ C, 1 C, 3 C, 5 C and 10 C, respectively.

Fig. 5 (a) Rate capability of these samples; (b) Capacity retention at different rates (Note, retention at $0.1 \mathrm{C}$ is $100 \%$ )

Fig. 6 shows the cycling performances of these samples at $0.2 \mathrm{C}$ between 2.0 and $4.8 \mathrm{~V}$ (inset), and the discharge curves for selected cycles. The L3 sample exhibits the optimal cycling stability, delivering a discharge capacity nearly $256 \mathrm{mAh} \mathrm{g}^{-1}$ at first cycle, and maintaining $251 \mathrm{mAh} \mathrm{g}^{-1}$ after 50 cycles with capacity retention of $98 \%$. Similar to the rate performance, the L4, L5 samples display the poorest cycle capability, with capacity retention of $86 \%$ and $83 \%$, respectively. Additionally, in order to exactly investigate the voltage fading upon cycling, the $1^{\text {st }}$ and $50^{\text {th }}$ discharge profiles of these samples after normalization of capacity are shown in Fig. S2. Clearly, the discharge curves of L3 sample exhibits the best consistency and delivers the lowest voltage decay with $\Delta=0.091 \mathrm{~V}$ for the voltage fading at the half capacity. This analysis indicates that the fast voltage fading upon cycling can be alleviated in L3 sample, and this novel molten salt method provides a simple and convenient way to address a huge challenge of layered-spinel intergrowth that could significantly lower the energy density of the whole battery. ${ }^{14,16}$ 

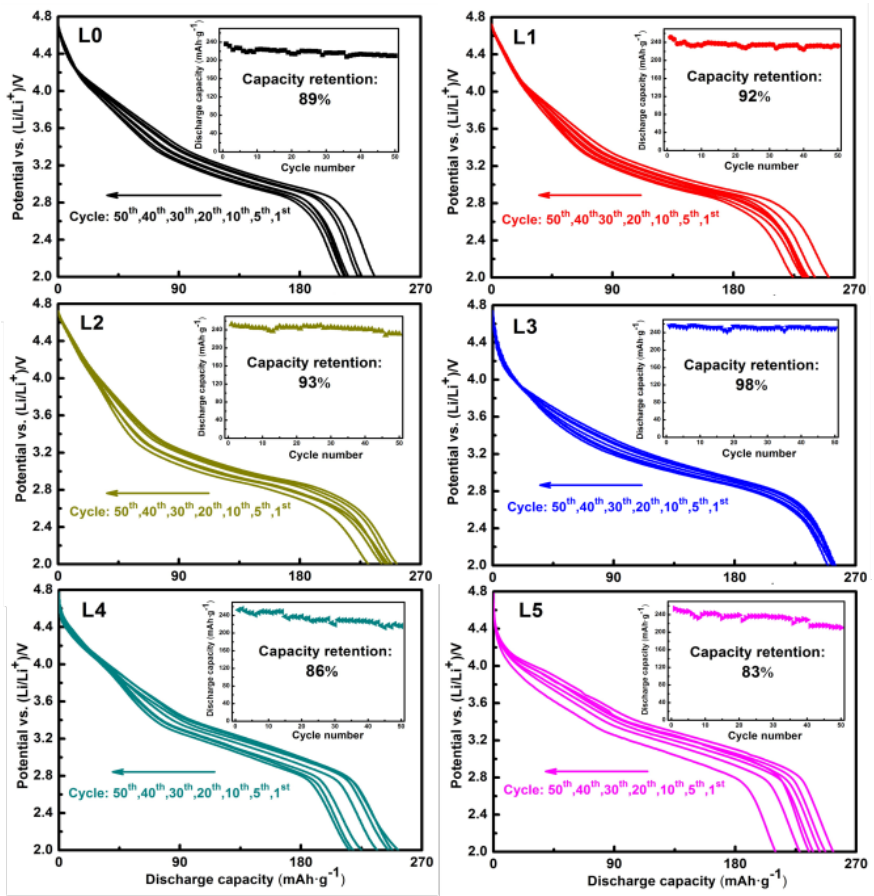

Fig. 6 Cycling stability of these samples at $0.2 \mathrm{C}$ between 2.0 and $4.8 \mathrm{~V}$ (inset), and the discharge curves for selected cycles

(a)

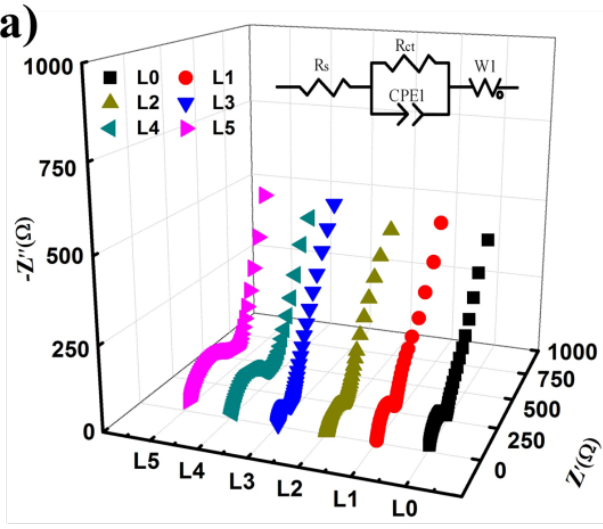

Electrochemical impedance spectroscopy (EIS) has been performed to investigate the difference in electrochemical performance of the samples. The measurements are carried out after the electrochemical examination of Fig. 5a. All Nyquist plots are shown in Fig. 7a, and the corresponding equivalent circuits are presented in the inset. In this equivalent circuit, $R$ s represents the resistance of the electrolyte and cell components, Rct corresponds to charge transfer resistance in the electrode-electrolyte interfaces, and W1 is the Warburg impedance for depicting $\mathrm{Li}^{+}$ion diffusion process in the electrode materials. ${ }^{42-44}$ Each impedance spectrum is fitted well with suggested equivalent circuit model, and the histogram (Fig. 7b) shows the variation of the corresponding fitted parameters. By monitoring these samples, a similar variation trends are found that the $R \mathrm{~s}$ remains almost unchanged, whereas the $R \mathrm{ct}$ is decreased firstly from L0 to L3 sample, and then increased quickly to L5 sample. The much lower Rct value for L3 sample is beneficial for reversible lithium ion de-intercalation and intercalation during repeated charge and discharge processes, leading to the better electrochemical performance. ${ }^{42-44}$ The lower Rct for L3 sample can be ascribed to the expansion of $c$-parameter and the well-defined $\alpha$ $\mathrm{NaFeO}_{2}$ layered structure leading to faster charge-transfer reactions in the electrode-electrolyte interfaces.

Fig. 7 (a) Nyquist plots and corresponding equivalent circuit (inset) of these samples; (b) Histogram of the corresponding fitted parameters of the samples

\section{Conclusions}

A novel method is proposed for the first time to synthesize the lithium-rich $\mathrm{Li}_{1.5} \mathrm{Mn}_{0.75} \mathrm{Ni}_{0.25} \mathrm{O}_{2.5}$ material. This method innovatively combines the hydroxide co-precipitation method with the modified molten salt method, in which the co-precipitation method can realize the molecule-level mixing of the starting materials and the modified molten salt method with moderate excessive $0.5 \mathrm{LiNO}_{3}-0.5 \mathrm{LiOH}$ eutectic salts can reduce the water waste in the wash process. Different molar ratios $(1.55,1.65,1.75,1.85,1.95,2.05)$ of Li/M (M $=\mathrm{Ni}+\mathrm{Mn}$ ) are employed to elucidate the effect of the amount of salt flux on the final product. The structure, morphology and electrochemical performance of these materials are systematically investigated. Structural characterization indicates that the sample with the ratio of $\mathrm{Li} / \mathrm{M}=1.85$ has more well-defined $\alpha-\mathrm{NaFeO}_{2}$ structure and more enlarged Li layer spacing. The electrochemical measurements confirm that the $\mathrm{Li} / \mathrm{M}=1.85$ sample has a high initial (b)

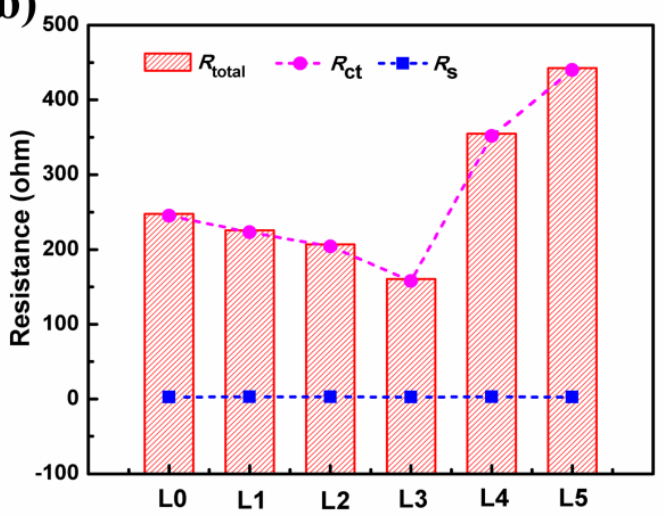

coulombic efficiency (87.86\%), greatly enhanced rate capability (129 $\mathrm{mAh} \mathrm{g}^{-1}$ at $10 \mathrm{C}$ ) and excellent cycling stability (98\% capacity retention after 50 cycles at $0.2 \mathrm{C}$ ). Moreover, the EIS results demonstrate that, compared to other samples, it has a significantly smaller charge transfer resistance $\left(R_{\mathrm{ct}}\right)$ because the expansion of $c$ parameter and the well-defined $\alpha-\mathrm{NaFeO}_{2}$ layered structure. We anticipate that this novel molten salt method provided insight into the design and synthesis of lithium-rich materials should inspire the development of a wide range of other stable, high rate and high capacity cathode materials.

\section{Acknowledgements}

This work was supported by the Science and Technology Pillar Program of Sichuan University (2014GZ0077), the Development of Advanced Electrode and Electrolytes for LIB (AutoCRC Project 1111), and the Research Fund for the Doctoral Program of Higher Education, the Ministry of Education (No. 20120181120103). 


\section{Notes and references}

${ }^{a}$ College of Chemical Engineering, Sichuan University, No.24 South Section 1, Yihuan Road, Chengdu, 610065, China. E-mail: zhongbenhe@163.com

${ }^{b}$ Department of Chemistry, College of Chemistry and Chemical Engineering, Xiamen University, Fujian 361005, China.

${ }^{c}$ Institute for Superconducting and Electronic Materials, Australian Institute for Innovative Materials, University of Wollongong, Innovation Campus, North Wollongong, NSW, Australia.

1. J.-M. Tarascon and M. Armand, Nature, 2001, 414, 359.

2. A. Manthiram, A. V. Murugan, A. Sarkar and T. Muraliganth, Energy Environ. Sci., 2008, 1, 621.

3. J. B. Goodenough and Y. Kim, Chem. Mater., 2010, 22, 587.

4. B. Dunn, H. Kamath and J.-M. Tarascon, Science, 2011, 334, 928.

5. H.-C. Yu, C. Ling, J. Bhattacharya, J. C. Thomas, K. Thornton and A. V. d. Ven, Energy Environ. Sci., 2014, 7, 1760.

6. J. B. Goodenough and K.-S. Park, J. Am. Chem. Soc., 2013, 135, 1167.

7. C. Yuan, H. B. Wu, Y. Xie and X. W. D. Lou, Angew. Chem. Int. Ed., 2014, 53, 1488.

8. A. Ito, D. Li, Y. Sato, M. Arao, M. Watanabe, M. Hatano, H. Horie and Y. Ohsawa, J. Power Sources, 2010, 195, 567.

9. G. Xu, J. Li, Q. Xue, X. Ren, G. Yan, X. Wang and F. Kang, J. Power Sources, 2014, 248, 894.

10. F. Fu, Y.-P. Deng, C.-H. Shen, G.-L. Xu, X.-X. Peng, Q. Wang, Y.-F. Xu, J.-C. Fang, L. Huang and S.-G. Sun, Electrochem. Commun., 2014, 44, 54.

11. J. Lin, D. Mu, Y. Jin, B. Wu, Y. Ma and F. Wu, J. Power Sources, 2013, 230, 76.

12. F. Cheng, Y. Xin, J. Chen, L. Lu, X. Zhang and H. Zhou, J. Mater. Chem. A, 2013, 1, 5301.

13. L. Zhang, B. Wu, N. Li, D. Mu, C. Zhang and F. Wu, J. Power Sources, 2013, 240, 644.

14. B. Xu, C. R. Fell, M. Chi and Y. S. Meng, Energy Environ. Sci., 2011, 4, 2223.

15. B. Song, H. Liu, Z. Liu, P. Xiao, M. O. Lai and L. Lu, Sci Rep, 2013, 3, 3094.

16. D. Mohanty, S. Kalnaus, R. A. Meisner, K. J. Rhodes, J. Li, E. A. Payzant, D. L. W. III and C. Daniel, J. Power Sources, 2013, 229, 239.

17. D. Li, T. Muta and H. Noguchi, J. Power Sources, 2004, 135, 262.

18. T. A. Arunkumar, Y. Wu and A. Manthiram, Chem. Mater., 2007, 19, 3067.

19. Y. Jiang, Z. Yang, W. Luo, X.-L. Hu, W.-X. Zhang and Y.H. Huang, J. Mater. Chem., 2012, 22, 14964.

20. X. He, J. Wang, R. Kloepsch, S. Krueger, H. Jia, H. Liu, B. Vortmann and J. Li, Nano Res., 2014, 7, 110.

21. W. ZhenYao, L. Biao, M. Jin and X. DingGuo, RSC Adv., 2014, 4, 15825.

22. X. Zhao, M. V. Reddy, H. Liu, G. V. S. Rao and B. V. R. Chowdari, RSC Adv., 2014, 4, 24538.
23. Y. Zhao, Y. Sun, Y. Yue, X. Hu and M. Xia, Electrochim. Acta, 2014, 130, 66.

24. C. Yu, G. Li, X. Guan, J. Zheng, L. Li and T. Chen, Electrochim. Acta, 2012, 81, 283.

25. M. V. Reddy, G. V. S. Rao and B. V. R. Chowdari, J. Phys. Chem. C, 2007, 111, 11712.

26. M.-H. Lee, Y.-J. Kang, S.-T. Myung and Y.-K. Sun, Electrochim. Acta, 2004, 50, 939.

27.M. M. Thackeray, S.-H. Kang, C. S. Johnson, J. T. Vaughey, R. Benedek and S. A. Hackney, J. Mater. Chem., 2007, 17, 3112.

28. M. M. Thackeray, C. S. Johnson, J. T. Vaughey, N. Li and S. A. Hackney, J. Mater. Chem., 2005, 15, 2257.

29. K. Kang, Y. S. Meng, J. Bre'ger, C. P. Grey and G. Ceder, Science, 2006, 311, 977.

30. T. Ohzuku, A. Ueda and M. Nagayama, J. Electrochem. Soc., 1993, 140, 1862.

31.X. Zhang, W. J. Jiang, A. Mauger, Q. Lu, F. Gendron and C. M. Julien, J. Power Sources, 2010, 195, 1292.

32. Z.-D. Huang, X.-M. Liu, S.-W. Oh, B. Zhang, P.-C. Ma and J.-K. Kim, J. Mater. Chem., 2011, 21, 10777.

33. H.-J. Noh, Z. Chen, C. S. Yoon, J. Lu, K. Amine and Y.-K. Sun, Chem. Mater., 2013, 25, 2109.

34. K. Amine, H. Tukamoto, H. Yasuda and Y. Fuiita, J. Electrochem. Soc., 1996, 143, 1607.

35. Q. Fu, F. Du, X. Bian, Y. Wang, X. Yan, Y. Zhang, K. Zhu, G. Chen, C. Wang and Y. Wei, J. Mater. Chem. A, 2014, 2, 7555.

36. P. G. Bruce, B. Scrosati and J.-M. Tarascon, Angew. Chem. Int. Ed., 2008, 47, 2930.

37. J. Bareño, M. Balasubramanian, S. H. Kang, J. G. Wen, C. H. Lei, S. V. Pol, I. Petrov and D. P. Abraham, Chem. Mater., 2011, 23, 2039.

38. C. Fu, G. Li, D. Luo, J. Zheng and L. Li, J. Mater. Chem. A, 2014, 2, 1471.

39. D. Luo, G. Li, X. Guan, C. Yu, J. Zheng, X. Zhang and L. Li, J. Mater. Chem. A, 2013, 1, 1220.

40. M. G. Kim, M. Jo, Y.-S. Hong and J. Cho, Chem. Commun., 2009, 218.

41. G.-Z. Wei, X. Lu, F.-S. Ke, L. Huang, J.-T. Li, Z.-X. Wang, Z.-Y. Zhou and S.-G. Sun, Adv. Mater., 2010, 22, 4364.

42. Y. Liu, Y. Gao and A. Dou, J. Power Sources, 2014, 248, 679.

43. Q. Li, G. Li, C. Fu, D. Luo, J. Fan and L. Li, ACS Appl. Mater. Interfaces, 2014, 6, 10330.

44. S. Wang, Y. Wu, Y. Li, J. Zheng, J. Yang and Y. Yang, Electrochim. Acta, 2014, 133, 100. 


\section{Supporting Information}

\section{Effective Enhancement of Electrochemical Performance for Layered Cathode $\mathrm{Li}_{1.5} \mathrm{Mn}_{0.75} \mathrm{Ni}_{0.25} \mathrm{O}_{2.5}$ via $A$ Novel Facile Molten Salt Method}

Zhuo Zheng, ${ }^{a}$ Wei-Bo Hua, ${ }^{a}$ Shi-Xuan Liao, ${ }^{a}$ Yan-Jun Zhong, ${ }^{a}$ En-Hui Wang, ${ }^{a}$ Bin-Bin Xu, ${ }^{b}$ Hua-Kun Liu ${ }^{c}$ and Ben-He Zhong* ${ }^{a}$

${ }^{a}$ College of Chemical Engineering, Sichuan University, No.24 South Section 1, Yihuan Road, Chengdu, 610065, China.

${ }^{b}$ Department of Chemistry, College of Chemistry and Chemical Engineering, Xiamen University, Fujian 361005, China.

${ }^{c}$ Institute for Superconducting and Electronic Materials, Australian Institute for Innovative Materials, University of Wollongong, Innovation Campus, North Wollongong, NSW, Australia.

*Corresponding author. Email: zhongbenhe@163.com 

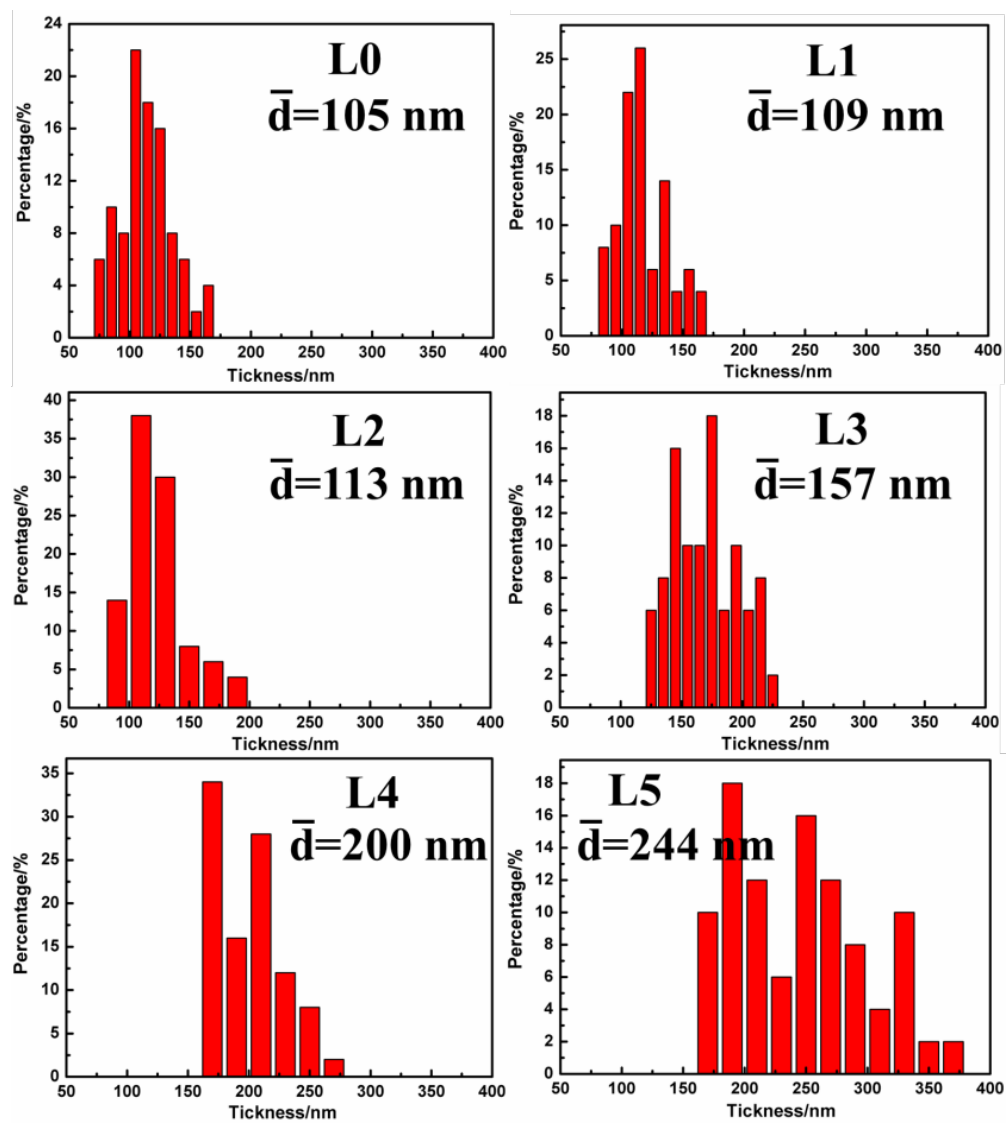

Fig. S1 Thickness distribution and the average thickness of L0 - L5 nanoplates 

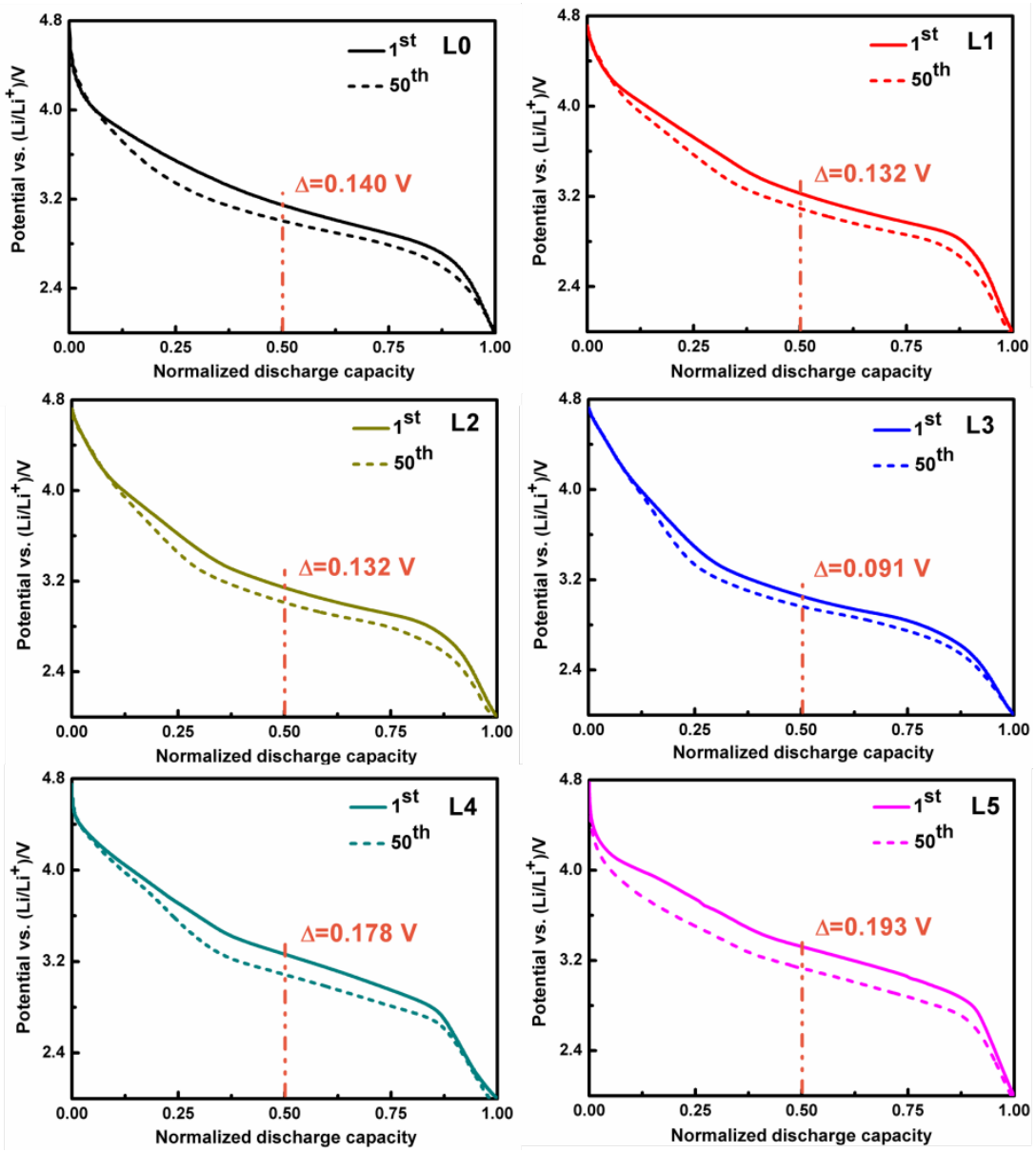

Fig. S2 Discharge profiles of $1^{\text {st }}$ and $50^{\text {th }}$ cycles of these samples at $0.2 \mathrm{C}$ after normalization of capacity 